\title{
Nachweis von Haptoglobinen und Isoagglutininen im Harn bei diabetischer Angiopathie
}

\author{
(Ein Beitrag zur Frage der glomerulären Filtration höhermolekularer Proteine)
}

Von

\author{
B. Gibe, R. Giebelmann, S. Martin, Friedelene Martin, M. Schulz und H. G. Lippilann
}

Aus dem Institut für Gerichtliche Medizin und Kriminalistik der Ernst-Moritz-Arndt-Universität Greifswald (Direktor: Prof, Dr. med. habil. E. ScHeIBE) und dem Institut für Diabetes ,Gerhardt Katsch" Karlsburg bei Greifswald (Direktor: Prof. Dr. med. habil G. MoHNIKE†)

Eingegangen am 9. August 1965

Summary. The object of this study was that of getting additional insight into the mechanism of proteinuria through analysis of the permeability of the glomerular filter for higher molecular weight proteins in patients with proteinuria resulting from diabetic nephropathy. Fifty hospitalized patients with insulin-requiring diabetes mellitus were selected according to the presence of proteinuria and divided into two groups: group I, with or without only minor symptoms of diabetic angiopathy; group II, with moderate to severe diabetic nephropathy and retinopathy grades 1 to 3 . In all patients the urinary excretion of haptoglobins (Hp) and of isoagglutins (IA) was measured, as well as the Hp level in the serum and the overall profile of serum and urine proteins. The results indicate that the urinary excretion of $\mathrm{Hp}$ and $\mathrm{TA}$ could be correlated to some extent with the severity of diabetic nephropathy, whereas the serum level of $H p$ failed to exhibit any clear-cut anomalies in the presence of diabetic angiopathy. In patients with severe nephropathy, the albumin/globulin ratio in the urine was increased approximately twofold over that in serum, despite a grossly unaltered profile of serum proteins. These results suggest that the "functional pore size" of the renal filter is increased in diabetic nephropathy, but that the mechanism of proteinuria also involves degradation of serum proteins during passage through the kidney.

Résumé. Ce travail analyse la perméabilité du filtre glomérulaire aux protéines de poids moléculaire plus élevé chez des malades atteints de protéinurie résultant de néphropathie diabétique. Il a porté sur 50 malades hospitalisés souffrant d'un diabète insulino-dépendant présentant tous une protéinurie et divisés en deux groupes. Groupe I: sans signe ou symptôme d'angiopathie diabétique, ou avec signes minimes seulement; groupe II: avec néphropathie modérée ou sévère et rétinopathie de sévérité 1 à 3 . Ont été mesurées l'excrétion urinaire d'haptoglobines $(\mathrm{Hp})$ et d'isoagglutinines (IA) ainsi que le taux d'Hp dans le sérum et le profil des protéines urinaires et sériques. Les résultats démontrent un certain degré de corrélation entre l'excrétion urinaire d'Hp et d'IA et la sévérité de la néphropathie diabétique, mais aucune corrélation entre le taux sérique d'Hp et l'angiopathie diabétique. Chez les malades atteints de néphropathie sévère le quotient albumine/globuline urinaire était approximativement le double de celui observé dans le sérum, malgré le profil normal des protéines sériques. Ces résul tats indiquent done que le "diamètre fonctionnel» des pores du filtre rénal est augmenté dans la néphropathie diabétique, mais également que le mécanisme de la protéinurie est accompagné de dégradation des protéines sériques au cours de leur transit rénal.

Zusammenfassung. Um einen weiteren Aspekt zum Mechanismus der Proteinurie, dessen Natur noch immer als nicht vollkommen geklärt gelten muß, zu gewinnen, war es das Anliegen dieser Arbeit, die Durchlässigkeit des glomerulären Filters für höhermolekulare Proteine bei einer durch diabetische Nephropathie hervorgerufenen Proteinurie zu untersuchen. Dazu wurden 50 stationär behandelte Patienten mit einem insulinpflichtigen Diabetes mellitus nach dem Merkmal einer Proteinurie ausgewählt und nach klinischen sowie labordiagnostischen Daten in zwei Gruppen eingeteilt: Gruppe $\mathbf{I}=$ keine oder nur leichte Symptome einer diabetischen Angiopathie, Gruppe II = mittlere bis sehwere diabetische Nephropathie und Retinopathie I. bis III. Grades. Untersucht wurde die Ausscheidung von Haptoglobinen ( $\mathrm{Hp}$ ) und Isoagglatininen (IA) im Harn, der Serum-Hp-Spiegel sowie das Verhalten von Serum- und Harnproteinogramm. Die Befunde lassen erkennen, daß die Ausscheidung von $\mathrm{Hp}$ und IA im Harn in gewissem Umfang dem Schweregrad der diabetischen Nephropathie korrelierbar ist, wobei der Serum-Hp-Spiegel bei diabetischer Angiopathie keine eindeutigen Veränderungen zeigt. Bei im ganzen unauffälligem Serumproteinogramm ist der Albumin-GlobulinQuotient im Harn gegenüber dem im Serum bei Patienten mit schwerer Nephropathie um etwa das Doppelte er. höht. Unter Berücksichtigung der Tatsache, daß die physikalisch-chemische Integrität der Harn-Hp zwar bereits nachgewiesen werden konnte ${ }^{22}$, die der IA aber bisher noch nicht, könnten die mitgeteilten Befunde ein Hinweis dafür sein, daß die Proteinurie bei diabetischer Nephropathie durch eine Vergrößerung des funktionellen „Porendurchmessers" des Nierenfilters verursacht wird.
Am. Zustandekommen einer Eiweißausscheidung durch die Niere sind offenbar mehrere (renale) Faktoren beteiligt. Unter physiologischen Bedingungen werden Serumeiweiße in der Regel bis zu einem Molekulargewicht von etwa $70000^{3}$ vom Glomerulum filtriert und sind im Primärharn nachweisbar 1, 9, 10, 12, 23, 49-51, 58, 59, jedoch ist die ,physiologische Proteinurie" nur sehr gering1, 12, 23, 50, 59. Für den Mechanismus einer
Proteinurie im klinischen Sinne wird daher angenommen, daß er in einer erhöhten glomerulären Durchlässigkeit für Eiweiß (Größerwerden der ,,Poren“ des Filters) zu suchen ist, vor allem deshalb, weil auch Serumeiweiße, die mit ihrem Molekulargewicht über der angenommenen Durchlässigkeitsgrenze liegen (Globuline u.a.), im Harn erscheinen ${ }^{5}$, 6, 25, 30, 40, 47; nach Untersuchungen dieser Autoren soll es sich jedoch bei 
den Harnglobulinen um Bruchstücke (kleinere Sedimentationskonstante) der Serumglobuline handeln, die bei der Nierenpassage durch proteolytische Spaltungen entstehen. Diese Hypothese konnte im übrigen durch FrankLIN $1959^{15}$ mit ${ }^{131} \mathrm{~J}$-markiertem $7 S$ - $\gamma$-Globulin, das er mit einer Sedimentationskonstante von $S=$ 1.1-2.6 wiederfand, bestätigt werden. Da aber bei manchen Proteinurien auch serumidentische Globuline nachweisbar waren ${ }^{26}$ and andererseits der AlbuminGlobulin-Quotient in Serum und Harn als nicht identisch erkannt wurde, mußte die Filtration als alleinige Ursache der Proteinurie in Zweifel gezogen und angenommen werden, daß eine tubuläre Proteinsekretion möglich $\mathrm{se}^{33}$, für deren Existenz jedoch bisher keine experimentellen Nachweise erbracht werden konnten ${ }^{40}$, 50. Als unbestrittener zweiter kausaler Faktor der Proteinurie gilt dagegen die tubuläre Rückresorption von Eiweiß4, 20, 31, 32, 36, 56, 57, so daß das Ausmaß der Proteinurie bei gleichbleibender oder gar erhöhter glomerulärer Eiweißfiltration offenbar erheblich durch eine verminderte tubuläre Rückresorption beeinflußt sein $\mathbf{k a n n}^{50}$.

Die bisherige experimentelle Bearbeitung dieser Problematik konzentrierte sich im wesentlichen auf den Versuch, die „Poren"-Größe des Nierenfilters unter den verschiedensten Bedingungen zu ermitteln ${ }^{26}, 34,40,42,43$. Wegen der nachgewiesenen Aufspaltung präformierter Serumeiweiße während der Nierenpassage ist es jedoch außerordentlich schwierig, aus der Beurteilung der Molekülgröße dieser Proteine Rückschlüsse auf die Durchlässigkeit der filtrierenden Fläche zu ziehen. Deshalb wurden insbesondere nichtphysiologische Makromoleküle (Dextran, Polyvinylpyrrolidon) mit differenten, definierten Molekülgrößen eingesetzt, ohne daß bis heute, obwohl bereits sehr fundierte Erkenntnisse ${ }^{34,42,43,52,60}$ vorliegen, eine endgültige Klärung des Mechanismus der Proteinurie herbeizuführen war.

Uns interessierte diese Problematik im Zusammenhang mit der bei einer diabetischen Nephropathie auftretenden Proteinurie, für deren Genese die Bedeutung des glomerulären Filters noch immer diskutiert wird ${ }^{8}$, 11, 24, 27, 34, 40, 50. Zu diesem. Zweck schienen sich uns die Haptoglobine und Isoagglutinine als Modell-Eiweißkörper anzubieten. Nach ihrer Ausscheidung im Harn suchten wir bei diesem Krankheitsbild deshalb, weil diese im Serum vorhandenen höhermolekularen Proteine mit charakteristischen Eigenschaften (Hämoglobinbindung, Agglutination), sofern sie im Harn intakt nachweisbar sind, das Nierenfilter mit hoher Wahrscheinlichkeit in toto passiert haben müssen (nach CooNs ${ }^{9},{ }^{10}$ verändern sich die immunologischen Merkmale bei Aufnahme der Proteine in die Tubuluszelle) und Rückschlüsse auf die Beschaffenheit des glomerulären Filters zu ziehen erlauben.

Ein Nachweis von Haptoglobinen im Harn erfolgte bisher nur in geringem Umfang bei Gesunden und bei Patienten mit verschiedenen Erkrankungen ${ }^{2,3,5,6,28}$, 29, ${ }^{35}$, jedoch nicht bei Patienten mit Diabetus mellitus; lediglich Bergstrand u. Mitarb. ${ }^{7}$ sowie Prokop und BUNDSCHUH ${ }^{45}$ berichteten über Serumhaptoglobin bei Diabetes mellitus. Die Erfassung von Isoagglutininen im Harn ${ }^{17,54}$ wurde bisher nicht beschrieben.

\section{Methodik}

Zur Untersuchung kamen Blut- und Harnproben von 50 Patienten, die an einem insulinpflichtigen Diabetes mellitus erkrankt waren und sich wegen einer Stoffwechselkontrolle bzw. Behandlung der diabetischen Komplikationen in unserer Klinik stationär aufhielten; sie wurden lediglich nach dem Merkmal einer Proteinurie ausgewählt und einmal nach der klinischen Symptomatik (Anamnese, Blutdruck, ophthalmologische und nephrologische Befunde u. a.), zum anderen nach Laboratoriums-Daten (Rest-Stickstoff und Harnstoff im Blut, Inulin-, PAH-Clearance, quantitatives Harnsediment u.a.) in zwei Gruppen eingeteilt: Gruppe I zeigte bei bestehender Proteinurie nur wenig faßbare Symptome einer Nephropathie und daneben entweder keine oder eine leichte Retinopathie (1. und 2. Grades); Gruppe II wies eine Nephropathie mittleren bis schweren Grades und zusätzlich eine Retinopathie 1.-3. Grades auf.

Zur Bestimmung der Haptoglobine (Hp) als Hämoglobinbindungskapazität (HbBK) differenziert nach dem Typ $1-1,2-1$ und $2-2^{38,41,45}$ und der Isoagglutinine (IA) als Titer ${ }^{46}$ gelangte Nüchternblut aus der Cubitalvene und ferner der gesamte 24-Std-Harn $(7.00-7.00 \mathrm{Uhr})$; außerdem erfolgte eine quantitative Bestimmung (gravimetrisch nach SoHERRER$B_{A N G}$ und eine papierelektrophoretische Trennung (Grassmann-Hannia) der Serum- und Harneiweiße. Uber die Methodik der Aufarbeitung von Serum und Harn wurde bereits an anderem Ort ausführlich berichtet ${ }^{17,}{ }^{18}$.

Die Angabe sämtlicher Werte erfolgte als Mittelwert mit einfacher Standardabweichung, die Signifikanz der Unterschiede wurde mittels doppelter Varianzanalyse geprüft**.

\section{Ergebnisse}

1. Haptoglobine $(\mathrm{Hp})$

Die H.bBK des Serums betrug bei allen untersuchten Patienten im Mittel $150.0 \pm 10.0 \mathrm{mg} \%$ mit einer Verteilung der Hp-Typen $1-1(n=5), 2-1(n=$ 23) und $2-2(n=22,2$ davon wiesen keinen Diabetes mellitus, aber eine Nephropathie anderer Genese auf, in die Endauswertung kamen daher nur 20 Patienten des Typs 2-2). Alle Patienten wiesen im Mittel eine Proteinurie von $88,0 \pm 14,9 \mathrm{mg} \%$ auf; insgesamt fanden sich $31(=62 \%)$ Hp-,,Ausscheider", die sich aus den Harn-Hp-Typen $1-1(n=5), 2-1(n=18)$

* Wir danken Herrn Dipl.-Mathematiker E. JutzI auch an dieser Stelle herzlich für die teilweise Übernahme der mathematischen Bearbeitung. 


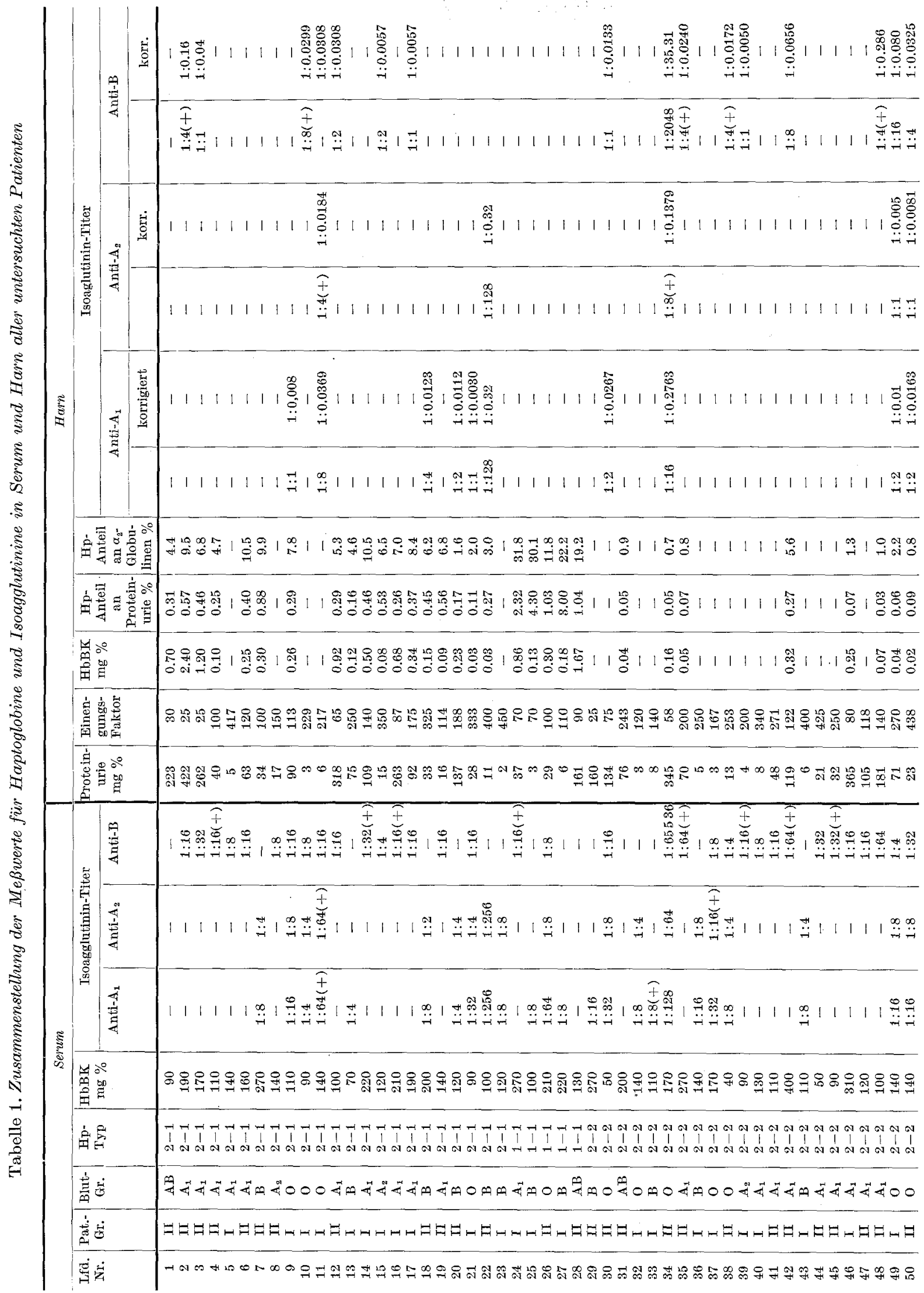


und 2-2 $(n=8)$ rekrutierten (Tab. 1). Wir konnten im Harn aller „Ausscheider" eine HbBK von $0.63 \pm$ $0.29 \mathrm{mg} \%(1-1) ; 0.47 \pm 0.14 \mathrm{mg} \%(2-1) ; 0.12 \pm$ $0.04 \mathrm{mg} \%(2-2)$, einen relativen Anteil der $\mathrm{Hp}$ am ausgeschiedenen Protein von $2.34 \pm 0.62 \%(1-1)$; $0.38 \pm 0.04 \%(2-1) ; 0.09 \pm 0.026 \%(2-2)$ und einen relativen Anteil der $\mathrm{Hp}$ an den Harn- $\alpha_{2}$-Globulinen von $23.02 \pm 3.61 \%(1-1) ; 6.42 \pm 0.63 \%(2-1)$; $1.66 \pm 0.59 \%(2-2)$ finden (Einzelwerte siehe Tab. 1).

Der Hp-Anteil am ausgeschiedenen Protein erwies sich weder vom Ausmaß der Proteinurie, noch von der Höhe der HbBK des Serums abhängig, jedoch konnten wir bei den beiden gebildeten Patientengruppen eine unterschiedliche Ausscheidung des $\mathrm{Hp}$ finden: die Gruppe II ( $n=12)$ schied mit $0.38 \pm 0.06 \% \mathrm{Hp}(2-1)$ Anteil am Harnprotein signifikant $(p<5 \%)$ mebr aus als die Gruppe $I(n=11)$ mit $0.18 \pm 0.06 \%$; darüberhinaus hatte die Gruppe II einen höheren Hp-Anteil an den $\alpha_{2}$-Globulinen des Harns $(5.7 \pm 0.94 \%)$ aufzuweisen als die Gruppe I $(3.9 \pm 1.15 \%)$, die Differenz ließ sich jedoch bei $p==5 \%$ nicht sichern (Tab. 2).

\section{Isoagglutinine (IA)}

Bei einem IA-Titer im Serum aller Patienten von $1: 2$ bis $1: 256$ beobachteten wir folgende Verteilung der einzelnen Blutgruppenmerkmale: $A_{1}: n=21, A_{2}$ : $n=3, \mathrm{~A}_{2} \mathrm{~B}: n=1, \mathrm{~B}: n=12, \mathrm{O}: n=13$.

Der Nachweis von IA im Harn gelang in 21 Fällen (= $42 \%$ ); bei einem Einengungsfaktor von 25 bis 450 (einzelne Werte siehe Tab. 1) fanden sich IA-Titer von 1:2 bis 1:128. Die Verteilung der Titer ermöglichte auch nach Normierung $\left(\frac{\text { Titer }}{\text { Einengungsfaktor }}=\right.$, , korrigierter'Titer" ) siehe Tab. 1 keine Bildung einzelner Gruppen, so daß lediglich eine einfache Häufigkeitsverteilung zur Beurteilung herangezogen werden kann (Tab. 3).

Die IA-, ,Ausscheider" sind auf die Patientengruppe I mit $n=8$, auf die Gruppe II mit $n=13$ verteilt, von den ,Nichtausscheidern" finden sich 12 in der Gruppe I und 17 in der Gruppe II. Bezogen auf die Blutgruppenmerkmale sind die (relativ) meisten IA-,,Ausscheider ${ }^{c}$ in der Blutgruppe 0 beobachtbar, während die Merk-

Tabelle 2. Haptoglobine in Serum und Harn diabetischer Patienten

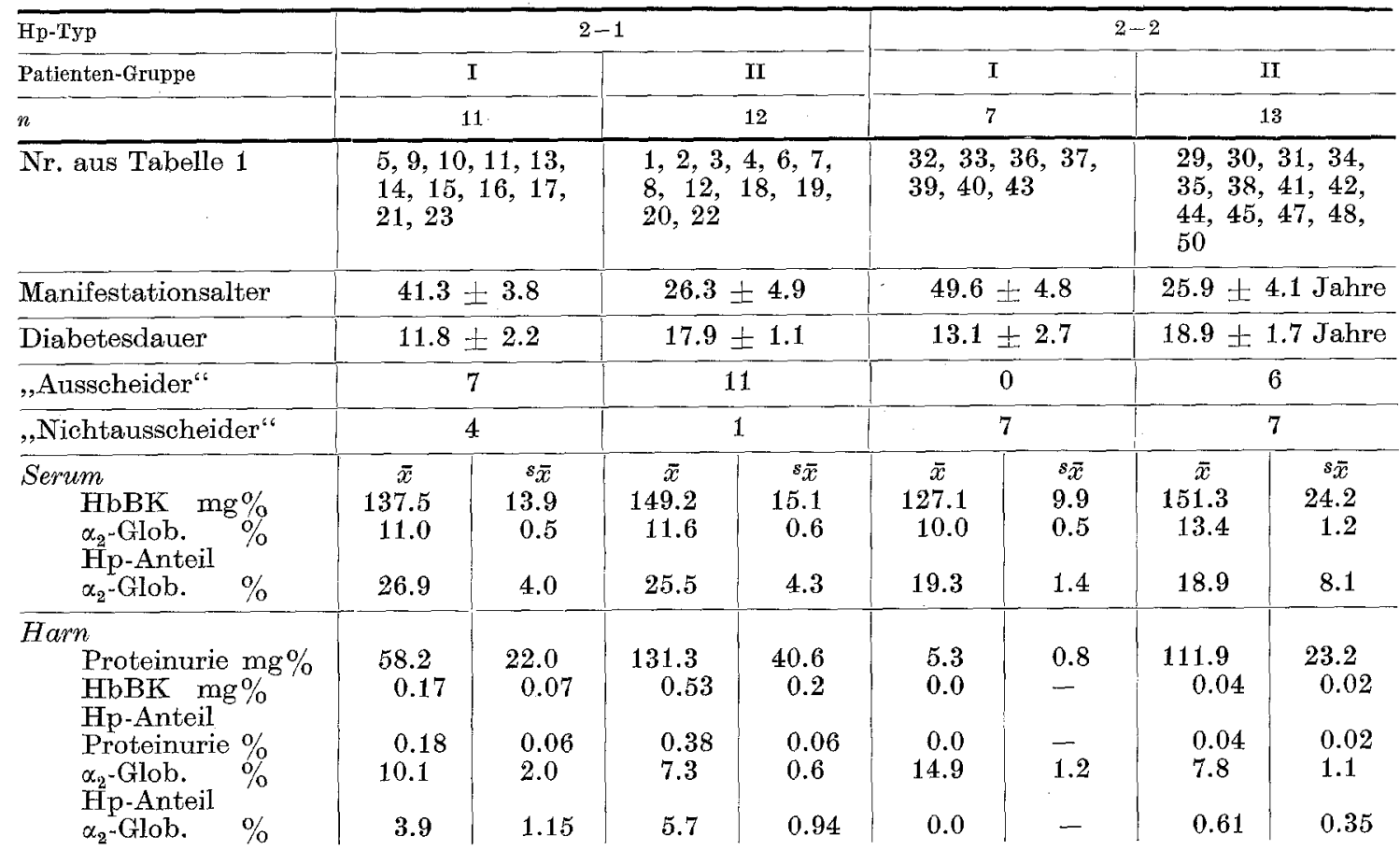

Alle Träger des Serum-Hp-Typs 1-1 $(n=5)$ waren auch ,Ausscheider" ${ }^{*}$, wegen der geringen Anzahl ließ sich jedoch eine sinnvolle Zuordnung $\mathrm{zu}$ den beiden Patientengruppen nicht vornehmen.

Unter den 20 diabetischen Patienten des Hp-Typs 2-2 fanden sich 6 ,Ausscheider", die sämtlich zur Gruppe II gehörten; alle Patienten der Gruppe I ( $n=$ 7) hatten keine $\mathrm{Hp}$ im Harn, jedoch fanden sich unter den ,Nichtausscheidern" $(n=14)$ auch 7 aus der Gruppe II (Tab. 2).
Tabelle 3. Ausscheidung von Isoagglutininen im Harn diabetischer Patienten und Verteilung der einzelnen Blutgruppenmerkmale

\begin{tabular}{|c|c|c|c|c|c|c|}
\hline $\begin{array}{l}\text { Pat.-Gruppe / Blut- } \\
\text { gruppenmerkmal }\end{array}$ & $\mathrm{I}$ & II & $A_{1}, A_{2}$ & $\mathrm{~A}_{2} \mathrm{~B}$ & B & o \\
\hline Merkma'lträger & & & 24 & 1 & 12 & 13 \\
\hline ,Ausscheider" & 8 & 13 & 9 & - & 3 & 9 \\
\hline $\begin{array}{l}\text { "Nicht- } \\
\text { ausscheider" }\end{array}$ & 12 & 17 & 15 & 1 & 9 & 4 \\
\hline
\end{tabular}


male $A_{1}, A_{2}$ und $B$ zum überwiegenden Teil von „Nichtausscheidern" besetzt werden (Tab. 3).

\section{Elelktropherogramme}

Um eine grobe Orientierung über die qualitative Zusammensetzung der Serum- und Harnproteine in den beiden Patientengruppen zu erhalten, erfolgte die papierelektrophoretische Auftrennung von Serum und Harnkonzentrat aller Patienten. Die Werte der einzelnen Proteinfraktionen bei den Trägern des Hp-Typs 2-1 und 2-2 sind in der Tabelle 4 zusammengestellt; bei dieser Aufstellung wurde lediglich die Trennung in in allen Fraktionen erkennen läßt: in der Gruppe I des Typs 2-2 sind gegenüber allen anderen Gruppen die Albumine stark erniedrigt, die $\alpha_{1^{-}}, \alpha_{2^{-}}$und $\gamma$-Globuline um etwa das doppelte und die $\beta$-Globuline etwas geringer erhöht.

Zur Gewinnung eines weiteren Aspektes bildeten wir aus den Werten der Serum- und Harnproteinogramme den Albumin-Globulin-Quotienten $(\bar{A} / G)$ und ordneten ihn jeweils den Patientengruppen I und II zu, die wir in IA-,,Ausscheider" und IA-,Nichtausscheider" unterteilten (Tab. 5).

Die Werte für den Serum-A/G sind zwischen den

Tabelle 4. Elektropherogramme der Serum- und Harnproteine bei diabetischen Patienten mit den Hp-Typen 2-1 und 2-2. Die Werte sind in relativen Prozenten als $\bar{x} \pm{ }^{s} \bar{x}$ angegbeen

\begin{tabular}{|c|c|c|c|c|c|c|c|c|}
\hline \multirow{2}{*}{$\frac{\text { Hр-Тyp }}{\text { Pat.-Gruppe }}$} & \multicolumn{4}{|c|}{$2-1$} & \multicolumn{4}{|c|}{$2-2$} \\
\hline & \multicolumn{2}{|c|}{ I } & \multicolumn{2}{|c|}{ II } & \multicolumn{2}{|c|}{ I } & \multicolumn{2}{|c|}{ II } \\
\hline \multirow[t]{2}{*}{$n$} & \multicolumn{2}{|c|}{11} & \multicolumn{2}{|c|}{12} & \multicolumn{2}{|c|}{7} & \multicolumn{2}{|c|}{13} \\
\hline & Serum & Harn & Serum & Harn & Serum & Harn* & Serum & Harn* \\
\hline Albumine & $\begin{array}{r}46.97 \\
+\quad 2.00\end{array}$ & $\begin{array}{r}54.47 \\
+\quad 7.56\end{array}$ & $\begin{array}{r}46.63 \\
+\quad 3.25\end{array}$ & $\begin{array}{r}59.68 \\
+\quad 2.58\end{array}$ & $\begin{array}{r}47,14 \\
+\quad 2.72\end{array}$ & $\begin{array}{r}26.60 \\
\pm \quad 4.45\end{array}$ & $\begin{array}{r}41.13 \\
+\quad 2.94\end{array}$ & $\begin{array}{r}61.20 \\
\pm \quad 3.33\end{array}$ \\
\hline $\begin{array}{r}\text { Globuline } \\
\alpha_{1}\end{array}$ & $\begin{array}{r}6.70 \\
+\quad 0.44 \\
\end{array}$ & $\begin{array}{r}6.76 \\
\pm \quad 0.99 \\
\end{array}$ & $\begin{array}{r}6,73 \\
+\quad 0.35 \\
\end{array}$ & $\begin{array}{r}7.20 \\
+\quad 0.66 \\
\end{array}$ & $\begin{array}{r}7.08 \\
+\quad 0.38 \\
\end{array}$ & $\begin{array}{r}15.50 \\
+\quad 2.19 \\
\end{array}$ & $\begin{array}{r}7.14 \\
+\quad 0.53 \\
\end{array}$ & $\begin{array}{r}7.60 \\
+\quad 1.14 \\
\end{array}$ \\
\hline$\alpha_{2}$ & $\begin{array}{r}11.76 \\
\pm \quad 1.18\end{array}$ & $\begin{array}{r}9.59 \\
+\quad 2.10\end{array}$ & $\begin{array}{r}11.18 \\
\pm \quad 0.83\end{array}$ & $\begin{array}{r}7.38 \\
+\quad 0.56\end{array}$ & $\begin{array}{r}10.03 \\
\pm \quad 0.48\end{array}$ & $\begin{array}{r}14.97 \\
\pm \quad 1.20\end{array}$ & $\begin{array}{r}12.91 \\
+\quad 1.24\end{array}$ & $\begin{array}{r}7.65 \\
+\quad 1.18\end{array}$ \\
\hline$\beta$ & $\begin{array}{r}15.16 \\
\pm \quad 0.63\end{array}$ & $\begin{array}{r}14.71 \\
+\quad 2.32\end{array}$ & $\begin{array}{r}14.94 \\
\pm \quad 0.99\end{array}$ & $\begin{array}{r}11.73 \\
\pm \quad 0.57\end{array}$ & $\begin{array}{r}14.30 \\
\pm \quad 0.37\end{array}$ & $\begin{array}{r}17.00 \\
\pm \quad 1.72\end{array}$ & $\begin{array}{r}16.24 \\
\pm \quad 1.10\end{array}$ & $\begin{array}{r}11.33 \\
+\quad 0.69\end{array}$ \\
\hline$\gamma$ & $\begin{array}{r}19.26 \\
\pm \quad 0.77\end{array}$ & $\begin{array}{r}14.51 \\
\pm \quad 2.55\end{array}$ & $\begin{array}{r}20.52 \\
+\quad 1.55\end{array}$ & $\begin{array}{r}13.58 \\
+\quad 1.21\end{array}$ & $\begin{array}{r}21.44 \\
+\quad 2.41\end{array}$ & $\begin{array}{r}25.93 \\
\pm \quad 2.33\end{array}$ & $\begin{array}{r}22.21 \\
+\quad 2.08\end{array}$ & $\begin{array}{r}12.29 \\
+\quad 1.18\end{array}$ \\
\hline
\end{tabular}

* Die Differenzen ließen sich bei $p=1 \%$ statistisch sichern.

Tabelle 5. Albumin-Globulin-Quotient $(\bar{x} \pm s \bar{x})$ im Serum und Harn diabetischer Patienten ohne $(I)$ bzw. mit $(I I)$ diabetischer Nephropathie. Die Patienten wurden unter dem Kriterium der Isoagglutinin-Ausscheidung (IA-A) bzw. - Nichtausscheidung $(I A-N A)$ im Harn zusammengefaßt

\begin{tabular}{|c|c|c|c|c|c|c|c|c|c|c|}
\hline \multirow[t]{2}{*}{ Patienten-Gruppe } & \multicolumn{5}{|c|}{ I } & \multicolumn{5}{|c|}{ II } \\
\hline & \multicolumn{2}{|c|}{ IA-A } & \multicolumn{3}{|c|}{ IA-NA } & \multicolumn{2}{|c|}{ IA-A } & \multicolumn{3}{|c|}{ LA-NA } \\
\hline \multirow[t]{2}{*}{$n$} & \multicolumn{2}{|c|}{8} & \multicolumn{3}{|c|}{17} & \multicolumn{2}{|c|}{13} & \multicolumn{3}{|c|}{12} \\
\hline & $\bar{x}$ & $s \bar{x}$ & $\bar{x}$ & $s \bar{x}$ & $p$ & $\bar{x}$ & $s \bar{x}$ & $\bar{x}$ & ${ }^{s} \bar{x}$ & $p$ \\
\hline Serum & 0.99 & 0.06 & 0.92 & 0.08 & $>5 \%$ & 0.95 & 0.20 & 0.79 & 0.06 & $>5 \%$ \\
\hline$p \%$ & \multicolumn{2}{|c|}{$>5$} & \multicolumn{3}{|c|}{$>5$} & \multicolumn{2}{|c|}{1} & \multicolumn{2}{|c|}{1} & \\
\hline
\end{tabular}

die Gruppen I und II, dagegen nicht eine Aufteilung in Hp-,,Ausscheider" bzw. -,Nichtausscheider" vorgenommen.

Bei den Trägern des Hp-Typs 2-1 finden sich sowohl im Serum- als auch im Harnproteinogramm keine statistisch signifikanten Unterschiede zwischen Gruppe I und II und ebenfalls weisen die Patienten des HpTyps 2-2 keine Unterschiede im Serumproteinogramm zwischen Gruppe I und II auf, während das Harnproteinogramm signifikante Differenzen $(p=1 \%)$ einzelnen Gruppen nicht signifikant verschieden, ebenso ergibt ein Vergleich des Harn-A/G innerhalb der 4 Gruppen keine signifikante Differenz. Dagegen ist in allen Gruppen, und zwar bei ,Ausscheidern" und „Nichtausscheidern" in gleicher Weise der Harn-A/G gegenüber dem Serum-A/G deutlich erhöht. Diese Frhöhung ist jedoch nur in der Gruppe II (Patienten mit schwerer Nephropathie) bei $p=1 \%$ signifikant, während sie in der Gruppe I nicht gesichert werden konnte (Tab. 5). 


\section{Besprechung der Ergebnisse}

Um einen weiteren Aspekt zum Mechanismus der Proteinurie, dessen Natur noch immer als nicht vollkommen geklärt gelten muß, zu gewinnen, war es das Anliegen dieser Arbeit, die Durchlässigkeit des glomerulären Filters für höhermolekulare Proteine bei einer durch diabetische Nephropathie hervorgerufenen Proteinurie zu untersuchen. Haptoglobine und Isoagglutinine schienen uns dafür besonders geeignet $\mathrm{zu}$ sein, denn sie liegen mit ihrem Molekulargewicht deutlich über der angenommenen (statistischen) Durchlässigkeitsgrenze des Nierenfilters ${ }^{3}$; das Gelingen ihres Nachweises mittels Hämoglobinbindung und Agglutination scheint an ihre Integrität gebunden zu sein $^{9},{ }^{10}$, und im übrigen gelang es HERMAN-BOUssIER $u$. Mitarb. ${ }^{22}$, Harn-Hp eines Nephrotikers als chemischphysikalisch identisch mit dessen Serum-Hp nachzuweisen. Wir dürfen daher annehmen, daß der spezifische Nachweis dieser beiden Proteine im Harn Aussagen über die funktionelle „Porengröße“ des glomerulären Filters zu treffen gestattet.

Die diabetische Nephropathie ist durch eine Reihe von funktionellen Fehlleistungen und ihnen zugeordneten morphologischen Veränderungen gekennzeichnet ${ }^{11}$ 21, 24, 27, 39, auf deren Einzelheiten im Rahmen dieser Arbeit nicht eingegangen werden soll.

Eine hochgradige Proteinurie bei Diabetes mellitus kann in nahezu jedem Falle einer schweren diabetischen Nephropathie zugeordnet werden, obwohl durchaus nicht jede diabetische Nephropathie zwangsläufig von einer Proteinurie begleitet wird ${ }^{27}$, 39. Nach Untersuchungen der meisten Autoren sind die dabei auftretenden Harnproteine nur selten identisch mit den Serumproteinen (dies gilt insbesondere für die Globuline) ${ }^{26}, 30,34$ und es wird angenommen, daß es in der Basalmembran, die bei der diabetischen Nephropathie typische Veränderungen zeigt ${ }^{11},{ }^{24},{ }^{40}, \mathrm{zu}$ einer Degradation der Serumproteine kommt ${ }^{30,}{ }^{34}$, wobei offenbar auch die Deckzellen ${ }^{40}$ und andererseits immunologische, im Glomerulum lokalisierte Prozesse ${ }^{8}$ pathogenetisch möglicherweise eine entscheidende Rolle spielen.

Die Haptoglobine, die mit ihrem Molekulargewicht deutlich über der Durchlässigkeitsgrenze der Niere liegen, wurden zwar in geringem Ausma $B$ auch im Harn Gesunder beobachtet ${ }^{5}$ 6, 28, 29, doch eine stärkere Ausscheidung konnte nur bei Nierenveränderungen, insbesondere bei nephrotischem Syndrom, nachgewiesen werden ${ }^{35}$, dabei handelte es sich stets um die Typen 1-1 und 2-1, während 2-2 niemals gefunden wurde. Erst kürzlich gelang der Nachweis auch des Hp 2-2 bei schwerer Nierenschädigung durch Schedrlen ${ }^{50,51}$. Da der Hp-Typ 2-2 das höchste Molekulargewicht besitzt (1-1 MG 85000, $S=4.5$; 2-1 MG 160000, $S=4.5-7 ; 2-2$ MG $400000, S=$ $7-8)^{53}$, liegt die Deutung nahe, daß die Durchlässigkeit der Niere für großmolekulare Eiweißkörper mit der Stärke ihres funktionellen (als Ausdruck des morpholo- gischen?) Schadens zunimmt; eine Hypothese, die schon früher von verschiedenen Autoren ${ }^{26}, 34,50,52,60$ geäußert wurde. So fanden wir in unseren Untersuchungen bei Patienten mit keinem oder nur leichtem Nierenschaden (Gruppe I) eine Ausscheidung der HpTypen 1-1 und 2-1 (wobei die Differenz zwischen Gruppe I und Gruppe II im Hp-(2-1)-Anteil am ausgeschiedenen Eiweiß statistisch mit $p<5 \%$ gesichert werden konnte), dagegen nicht des Typs 2-2 und bei Patienten mit schwerem Nierenschaden (Gruppe II) zunehmend mehr ,Ausscheider" des Typs 2-1 und darüberhinaus auch „Ausscheider" des Typs $2-2$.

Bei annähernd gleich großen Werten für die HbBK des Serums bei beiden Hp-Typen und jeweils beiden Gruppen sowie geringfügig erhöhten Werten des Hp(2-1)-Anteils an den $\alpha_{2}$-Globulinen sind die quantitativen Unterschiede in der Proteinurie zwischen den Gruppenpaaren I und II sehr beträchtlich (Tab. 2). Der Hp-Anteil an der Proteinurie, als auch der Hp-Anteil an den $\alpha_{2}$-Globulinen des Harns liegen bei gleicher Größe der $\alpha_{2}$-Globuline im Harn beim Typ 2-2 gegenüber dem Typ 2-1 um rund eine Zehnerpotenz niedriger. Aus diesen quantitativen Unterschieden muß geschlossen werden, daß (bei gleichhoher HbBK des Serums) eine quantitativ unterschiedliche Hp-Ausscheidung entsprechend dem Molekulargewicht stattfindet, die darüberhinaus bezogen auf den ausgeschiedenen Hp-Typ auch weitgehend unabhängig vom Ausmaß der Proteinurie ist (Tab. 2), so daß wir eine unmittelbare Beziehung zwischen der Schwere der diabetischen Angiopathie und der Hp-Ausscheidung sehen müssen und diese quantitativ unterschiedliche Ausscheidung der beiden Typen darauf hinweist, daß die Durchlässigkeit des Nierenfilters für höhermolekulare Proteine bei unserem untersuchten Patientengut graduell bis zu einem Molekulargewicht von 400000 ansteigen kann. Sofern der spezifische Nachweis des Haptoglobins tatsächlich an die Integrität des Proteinmoleküls bzw. seiner einzelnen Komponenten gekoppelt ist, könnten diese Befunde als ein Beweis dafür gelten, daß die ,funktionelle Porengröße" des glomerulären Apparates bei der diabetischen Nephropathie an Ausmaß zunimmt.

Den Serum-Hp-Spiegel konnten wir im übrigen bei allen Gruppen gegenüber dem geltenden Normalwert ${ }^{55}$ zwar bei einigen Patienten ein wenig erhöht (Tab. 1), aber statistisch nicht signifikant verändert finden, auch nicht bei den Gruppen mit schwerer Angiopathie, so daß wir die Meinung von Bergstrand u. Mitarb.?, die ihre Untersuchungen an jugendlichen Diabetikern durchführten, eine Erhöhung des Serum-Hp-Spiegels sei pathognomonisch für die diabetische Angiopathie, mit unseren Befunden nicht uneingeschränkt stützen können.

Brauchbare Beziehungen zwischen der unterschiedlich hohen Proteinurie und der Ausscheidung von Isoantikörpern im Harn fanden sich nicht. Das Vorkommen von Isoagglutininen läßt jedoch prinzi- 
piell die gleiche Aussage hinsichtlich einer erhöhten Durchlässigkeit des Nierenfilters zu: Patienten mit schwerer diabetischer Nephropathie (Gruppe II) scheiden relativ häufiger Isoagglutinine aus als die Patienten der Gruppe I (Tab. 3). Auffällig ist allerdings, daB sich in beiden Gruppen ein sehr hoher Anteil von „Nichtausscheidern“ findet. Nach Untersuchungen verschiedener Autoren ${ }^{14,61}$ stellen die Isoagglutinine keine einheitliche physikalisch-chemische Fraktion dar, sondern ein Gemisch aus sogenannten ,schweren" ( $S=19$ ) und ,leichten" $(S=7)$, wobei offenbar das Verhältnis zugunsten der einen oder der anderen Fraktion stark verschoben sein kann. Da einerseits auch bekannt ist, da B Anti-A- und Anti-B-Isoagglutinine des 19-S-Typs durch disulfidbrückenspaltende Reduktionsmittel, wie beispielsweise Merkaptane, in inaktive Bruchstücke gespalten werden ${ }^{25}$, und sich andererseits bei der Säulenchromatographie die in der Zwischenfraktion enthaltenen Antikörper (11-12-S-Antikörper nach RockeY und KUNKEL) ${ }^{48}$ immunologisch wie die in der $0.2 \mathrm{~m}$-(Phosphatpuffer)-Fraktion darstellbaren 19-S-Antikörper verhalten ${ }^{44}$, nehmen wir an, daß die im Urin nachgewiesenen Isoagglutinine nicht dem Typ der ,schweren “ Antikörper (MG 1000000) ${ }^{16}$ zuzuordnen sind. Bei dem hohen Anteil von ,Nichtausscheidern" in beiden Patientengruppen könnte das Mischungsverhältnis von ,,leichten" und ,schweren“ Antikörpern fast vollständig zugunsten des zweiten Typs verschoben sein. Eine endgültige kritische Wertung unserer Befunde ist allerdings erst dann möglich, wenn wir bei den Harn-Isoagglutininen Ultrazentrifugenstudien durchgeführt haben.

Unter Berücksichtigung der Molekulargewichtsverhältnisse für das Beta-Isoagglutinin ${ }^{13}$ lassen sich aus der Verteilung der ,Ausscheider" auf die einzelnen Blutgruppenmerkmale (Tab. 3) vorsichtig Anhaltspunkte für unsere geäußerte Hypothese gewinnen. Hiernach gehören die (relativ) meisten ,Ausscheider" zur Gruppe O ( $\beta[\mathrm{OO}] \mathrm{MG}$ 170000) und die (relativ) wenigsten zur Gruppe A ( $\beta\left[\mathrm{A}_{1} \mathrm{~A}_{1}\right] \mathrm{MG} 300000, \beta\left[\mathrm{A}_{1} \mathrm{O}\right]$ MG 500000) sowie zur Gruppe B. Hieraus könnte abgeleitet werden, daß das Nierenfilter bei diabetischer Nephropathie mindestens für Eiweiße mit einem Molekulargewicht bis 300000 durchlässig sein kann.

Die Veränderungen der Serum- und Harnproteinogramme, wie sie als charakteristisch für die diabetische Angiopathie beschrieben wurden ${ }^{26,}$ 27, 37, 39, 50 sind bei unseren untersuchten Patienten nicht deutlich ausgeprägt; dieser Tatbestand hat seine Ursache mit Sicherheit in der relativ geringen Anzahl der zur Beobachtung herangezogenen Fälle, zum anderen aber sind Verschiebungen im Pherogramm für den Diabetes mellitus auch ohne Angiopathie pathognomonisch 26, 27, ${ }^{39}$, so daß eine Differenz der Proteinogrammwerte zwischen unseren Gruppen I und II von vornherein nicht zu erwarten war.

Die beschriebenen Abweichungen im Harnproteinogramm zwischen Gruppe I und II bei den Trägern des Hp-Typs 2-2 (Tab. 4) möchten wir als zufällig be- dingt ansehen ( $n=7$ ), obwohl sie mathematisch als signifikant $(p=1 \%)$ gesichert werden konnten; es scheint unmöglich, dafür eine diskutierbare biologische Deutung zu geben.

Die Erhöhung des Albumin-Globulin-Quotienten im Harn gegenüber dem Quotienten im Serum um etwa das Doppelte ist bei den Patienten mit schwerer Nephropathie (Gruppe II) in gleicher Weise bei Isoagglutinin-,,Ausscheidern" und -,,Nichtausscheidern" statistisch signifikant, während bei den Patienten der Gruppe I die Quotienten in Serum und Harn als identisch angesehen werden müssen. Dieser Befund stützt die Hypothesen von LIss u. Mitarb. ${ }^{34}$ sowie K $\ddot{U} \mathbf{H N}^{\mathbf{3 0}}$, die fordern, daß, falls es sich nur um ein Weiterwerden der ,Poren" handele, der Albumin-Globulin-Quotient in Serum und Harn identisch sein müsse ${ }^{\mathbf{3 4}}$ bzw. ein Abweichen der Quotienten voneinander auf einer Degradation der Serum-Globuline, verursacht durch entsprechende Stoffwechselprozesse in der pathologisch veränderten Basalmembran, schließen läßt30, 34. Das erstere Verhalten würde sich in den Befunden unserer Gruppe I, das letztere in denen der Gruppe II widerspiegeln.

Unter Berücksichtigung der Tatsache, daß zwar für die Harn-Hp von anderen Autoren ${ }^{22}$, jedoch bisher nicht für die Harn-IA die physikalisch-chemische Integrität nachgewiesen werden konnte und ferner, daß in unserer Versuchsanordnung diese beiden höhermolekularen Proteine bei Patienten mit schwerem Nierenschaden vergleichsweise eindeutig vermehrt im Harn nachzuweisen waren, lassen die dargelegten Befunde also die Deutung zu, daß die erhöhte renale Durchlässigkeit für Proteine bei der diabetischen Nephropathie möglicherweise über ein Größerwerden. des "funktionellen Porendurchmessers" des Nierenfilters zustandekommen könnte.

\section{Literatur}

1 Apdis, T.: Glomerular nephritis, diagnosis and treatment. New York 1948.

${ }^{2}$ Baranyai, P., Zs. Czirbesz und Gy. Kapts: Beiträge zur Frage der Proteinurie. Elektrophoretische und immunelektrophoretische Untersuchungen der Serum- und Harneiweißstoffe bei Kindern mit Nephrose-Syndrom. Acta Paedjat. hung. 5, 339 (1964).

${ }^{3}$ Bayliss, J.F., F.H.T. Kerridge and D.S. Russel: The excretion of Protein by the mammalian kidney. J. Physiol. (Lond.) 77, 386 (1933).

4 Bennhold, H., O. Serbold und F. Kates: ${ }^{131} \mathrm{~J}$ Serumproteine und Farbstoffspeicherung. Z. Naturforsch. $10 \mathrm{~b}, 578$ (1955).

5 BERGGÁRD, I.: The plasma proteins in normal urine. Nature (Lond.) 187, 776 (1960).

6 - , und A.G. BEARN : Excretion of haptoglobin in normal urine. Nature (Lond.) 195, 1311 (1962).

7 Bergstrand, C.G., P. Fürst, Y. Larsson und G. STERKY: Serum haptoglobin in juvenile diabetes. Scand. J. clin. Lab. Invest. 14, 629 (1962).

${ }^{8}$ Berns, A.W., C.T. Owwes, Y. Hirata und K. F. BuUMENTHAL: The pathogenesis of diabetic glomeruloskerosis. Diabetes 11, 308 (1962).

${ }^{9}$ CoONs, A.H., and H.M. KAPLAN : Localisation of antigen in tissue cells. II. Improvements in a method for 
the detection of antigen by means of fluorescent antibodies. J. exp. Med. 91, 1 (1950).

10 - F.H. LEDUO and H.M. KapLAN: Localisation of antigen in tissue cells. VI. The fate of injected foreign proteins in the mouse. J. exp. Med. 93, 173 (1951).

11 Cosser, L., G. Lisewskr und G. MoHNike : Elektronenmikroskopische und klinische Untersuchungen bei der diabetischen Glomerulosklerose. Klin. Wschr. 37, 1005 (1959).

12 Ekehorn, G.: Die Natur des glomerulären Exsudationsprozesses: Sekretion oder Ultrafiltration nebst einigen Bermerkungen über direkte ehemische Untersuchung mikroskopischer Proben. Virehows Arch. 285, 443 (1932).

13 Filitti-Wurmser, S., Y. Jacquot-Armand, G. AubetLFSURE und R. WURMSER: Physico-chemical study of human isohaemagglutination. Ann. Eugen. 18, 183 (1954).

14 Fudenberg, H.H., H.G. Kunkel and E.C. Frankuin: High molecular weight antibodies. Acta haemat. 10, $522(1959)$.

15 Frankum, E.C.: Physicochemical and immunologic studies of gamma-globuline of normal human urine. J. clin. invest. 38, 2159 (1959).

16 - The Structure, Function and Significance of the Immune Globulins. Vox Sang. 7, 1 (1962).

17 GibB, B., M. Sohulz, G. Lodwig, R. GIEBeLmanN und E. SCHEIBE: Isolierung und Identifizierung von Blutgruppenantikörpern im Harn bei Proteinurie. Z ärztl. Fortbild. 60, 135 (1966)

18 Gimbelmavi, R., S. Martin und F. Martin: Serum konzentration und renale Ausscheidung von Haptoglobin bei Diabetikern mit Proteinurie. Ärztl. Lab. 11, 80 (1965).

19 - - - Serumkonzentration und renale Ausscheidung von Haptoglobinen bei Diabetikern. Mitt. Ges. exp. Med. DDR 1964, 3, 48 .

20 Grtuin, D.: Distribution of azo-protein in tissues of normal mouse. Proc. Soc. Exp. Biol. (N.Y.) 74, 138 (1950).

21 GRETF, St., und E. Moro: Die Bedeutung der Albuminurie beim Diabetes. Wien. klin. Wschr. 62, 515 (1950).

22 Herman-Boussier, G., J. Morettit et M.F. JaYLE: Etude de l'haptoglobine. II. Propriétés physiques et chimiques des haptoglobines des types I et II et de leurs complexes avec l'hémoglobine. Bull. Soc. Chim. biol. (Paris) 42, 837 (1960) zit. nach 51.

23 Heinzel, W.: Ausscheidung von ${ }^{131} \mathrm{~J}-\mathrm{H}$ umanalbumin im Primärharn der Froschniere. Z. Naturforsch. 14 b, $323(1959)$.

24 HoLLE, G.: Über elektronenmikroskopische Befunde bei diabetischer Angiopathie. Langenbecks Arch. Klin. Chir. 295, 253 (1960).

25 Jacot-Guilitarmod, H., und H. Istiker : Scission et réassociation des isoagglutinines traitées par des agents réducteurs des ponts disulfures. Préparation d'anticorps mixtes. Vox. Sang. 7, 675 (1962).

26 JAHNkE, K., und W. ScHoLtan: Zum Mechanismus der Proteinurie. Dtsch. Arch. klin. Med. 200, 821 (1953).

27 - K. IRMsChe und H. G. Solbach: Zur klinischen und morphologischen Differenzierung der renalen Komplikationen beim Diabetes mellitus. Klin. Wschr. 42, 259 (1964).

28 JAYLE, M. F. et G. Boussier : Obtention à l'état homogène d'une mucoprotéine sérique l'haptoglobine. Bull. Soc. Chim. biol. (Paris) 36, 959 (1954) zit. nach 51.

29 - - et M. J. Batras: Relations entre le taux de l'haptoglobine, celui des globulines $\alpha_{2}$ et des mucopolysaccharides circulants en pathologie. C.R. Soc. Biol. (Paris) 149, 46 (1955) zit. nach 51

30 KÜHN, R.A.: Eiweißtransport durch Glomerulum- kapillaren. Untersuchungen bei Kranken mit einer diabetischen Glomerulosklerose. Vortrag auf dem Elektronenmikroskopischen Kolloquium am 4. 10. 1964 in Leipzig.

3i Lambert, P.P., C. Matmendeier and J. P. de Coster : Blood volume and glomerular permeability to proteins. 6. Intern. Kongreß $\mathrm{f}$. innere Medizin Basel 1960; in: Pathogenese und Therapie der Oedeme (B. Schwabe, Basel 1960).

32 Lathem, W., B.E. Davis, P.H. Zweig and R. Dew: The demonstration and localisation of renal tubular reabsorption of hemoglobin by stop flow analysis. $\mathrm{J}$. clin. Invest. 39, 840 (1960).

${ }^{33}$ Lichтwitz, A. L. : Nephritis. (Grune und Stratton, New York 1942) zit. nach 24.

34 Lins, H., K. Jahnke und W. Scholtan: Úber die Permeabilität höhermolekularer Stoffe in der Niere bei diabetischen and anderen Nephropathien. III CIDF 1958 Stuttgart 1959, S. 203.

35 Marnay, A.: Haptoglobinuria in nephrotic syndromes. Nature (Lond.) 191, 74 (1961).

${ }^{36}$ Mayersbach, H., and A.G. E. Pearise: The metabolism of fluorescein-labelled and unlabelled egg-white in the renal tubules of the mouse. Brit. J. exp. Path. 37, $81(1956)$.

37 Mellinghoff, K., O. Glassen, M. Kuenitz und A. WIIDEMANN : Untersuchungen über das Bluteiweiß. bild beim Diabetes mellitus. Klin. Wschr. 29, 708 (1951).

38 MǗLER, K., und W. SOHELER: Zur Methodik der Haptoglobinbestimmg. Zschr. med. Labortechnik 4, 191 (1963).

${ }^{39}$ MoнnIKस, G.: Diabetische Angiopathie. Dtsch. Zschr. Verdauungskrkh. 22, 15 (1962).

40 Noltwentus, H. : Zellveränderungen an der Glomerulum. kapillarwand bei Proteinurie infolge Aminonucleosidvergiftung. Beitr. path. Anat. 128, 180 (1963).

41 Nyman, M.: Serum haptoglobin. Methodological and clinical studies. Scand. J. clin. Labor. Inv. 11, Suppl. $39(1959)$.

42 Ozawa, Y., and M. Yamaudeht: Studies on the changes of glomerular permeability in proteinuria. Keio J. Med. 12, 37 (1963).

43 Pappenhermer, J.R.: Über die Permeabilität der Glomerulummembran. Klin. Wschr. 33, 362 (1954).

44 Poltey, M. J., M. Adinolfi and P. L. Mollison: Serological Characteristics of Anti-A Related to Type of Antibody Protein (7 S $\gamma$ or $19 \mathrm{~S} \gamma$ ). Vox Sang. 8, 385 (1963).

45 Prokop, O., und G. Bundschur ; Die Technik und die Bedeutung der Haptoglobine und Gm-Gruppen in Klinik und Gerichtsmedizin. Berlin 1963.

46 - , und G. UHLENBRUCK: Lehrbuch der menschlichen Blut- und Serumgruppen. Leipzig 1963.

47 Rigas, D.A., and C.G. Heller: The amount and nature of urinary protein in normal human subjects. J. elin. Invest. 30, 853 (1951).

48 Rockey, J.H., und H.G. KUNKEL: Unusual sedimentation and sulphydryl sensitivity of certain isohemag. glutinin and slkinsensitivity antibody. Proc. Soc. exp. Biol. Med. 110, 101 (1962).

${ }^{49}$ Scheurlen, P.G.: Ưber Serumeiweißveränderungen bei Diabetes mellitus. Klin. Wschr. 33, 198 (1955).

50 - Untersuchungen über die Beziehungen zwischen Urin- und Serumeiweiß. Ein Beitrag zur glomerulären Eiweißfiltration. Habil.-Schr. Med. Fak. Tübingen 1961.

51 - Quantitative und qualitative Untersuchungen über die Eiweißausscheidung gesunder und kranker Nieren. Fortschr. Med. 81, 299 (1963).

52 Schubert, R., und R. HaUg: Neue Ergebnisse über die glomeruläre Ausscheidung verschiedener Molekülgrößen bei Nierengesunden, Glomerulonephritis 
und Nierenamyloid. Verh. dtsch. Ges. inn. Med. 67, $605(1961)$.

${ }^{53}$ Schultze, H. E., und K. Heine: Der neueste Stand der Plasmaproteinforschung in: K.F. BAUER Med. Grundlagenforschung Bd. 3, S. 351, Stuttgart 1960.

54 Schulz, M., R. Gtebelmann, G. Ludwig und B. GibB: Nachweis von Isoagglutininen im Harn von Diabetikern. Mitt. Ges. exp. Med. DDR 1964/3, 47.

55 Schuhmacher, G., und H.D. Schlumberger: Eigenschaften, Bestimmung und klinische Bedeutung von Haptoglobin. Klin. Wschr. 40, 67 (1962).

56 Seybold, O.: Die Bedeutung der Plasmaproteine und Mitochondrien für die Vitalspeicherung. Modellversuch für Transport und Stoffaustausch. Habil.Schr. Tübingen 1956.- Medizinische 1958, 1232.

57 SPECTOR, N.G.: The reabsorption of labelled protein by the normal and nephrotic rat kidney. J. Path. Bact. 68, 187 (1954).
58 Volhard, F.: Niere und ableitende Harnwege, in: Handb. inn. Med. Bd. 6/1 Berlin 1931.

59 Walker, A.L., P.A. BotT, J. Oliver and M.C. MCDOWELL: The collection and analysis of fluid from single nephron of the mammalian kidney. Amer. J. Physiol. 134, 580 (1941).

60 Wallenius, G.: Renal clearance of dextran as a measure of glomerular permeability. Acta Soc. Med. upsalien Suppl. 4 (1959).

61 Yokoyama, M., J.S. Finlayson, R.T. Suchinsky and N.E. RoBerTs: Chemical and serological characteristies of blood group antibodies in the ABO und Rh system. J. Immunol. 87, 56 (1961). Zit. nach 43.

Dr. med. B. GIBB

Institut für Gerichtliche Medizin und

Kriminalistik der Universität Greifswald 22 Greifswald, Schützenstr. 14 